\title{
Predictive Factors in Sacral Neuromodulation: A Systematic Review
}

\author{
Ranjana Jairam ${ }^{\mathrm{a}}$ Jamie Drossaerts ${ }^{\mathrm{a}}$ Tom Marcelissen $^{\mathrm{a}}$ \\ Gommert van Koeveringe ${ }^{a, b}, c$ Desiree Vrijens ${ }^{a, b}$ Philip van Kerrebroeck ${ }^{a, b}, c$ \\ aDepartment of Urology, Maastricht University Medical Centre (MUMC+), Mastricht, The Netherlands; bPelvic Care \\ Centre Maastricht, Maastricht University Medical Centre (MUMC+), Mastricht, The Netherlands; 'School of Mental \\ Health and Neuroscience (MHeNS), Maastricht University, Maastricht, The Netherlands
}

\section{Keywords}

Predictive factors · Sacral neuromodulation · Overactive bladder · Nonobstructive urinary retention · Lower urinary tract symptoms

\begin{abstract}
Introduction: Sacral neuromodulation (SNM) is an effective treatment in patients with overactive bladder syndrome or nonobstructive urinary retention when conservative treatment fails. Several factors that could impact outcome with SNM have been studied. This systematic review investigated these predictive factors and their relevance for clinical practice. Methods: Systematic review according to the PRISMA guidelines was conducted. This review is registered in the PROSPERO register (CRD42015016256). Results: Seventyeight studies (of which 11 abstracts) were included. Females, younger patients, and a tined lead procedure tend to be predictive in successful SNM outcome. Factors that did not influence SNM outcome were prior back surgery, surgery for stress urinary incontinence, affective symptoms, and duration of complaints. Reduced detrusor contractility is associated with a lower success rate. The level of evidence of most studies (graded according to the Centre for Evidence-Based
\end{abstract}

Medicine) was 3b. Conclusion: Even though this systematic review investigated predictive factors (gender, age, type of procedure, type of lead, and detrusor contractility), no general consensus on predictive factors could be made. Most studies are small, retrospective, and involve a heterogeneous population. Therefore, prospective research in larger specific patient groups remains necessary to find predictors of SNM outcome.

(c) 2021 The Author(s)

Published by S. Karger AG, Basel

\section{Introduction}

Sacral neuromodulation (SNM) is an effective treatment option in patients with lower urinary tract symptoms, when conservative treatment fails. Successful test stimulation is defined as a reduction of one or more micturition symptoms of $\geq 50 \%$ compared to baseline, determined by voiding diaries. Following a successful test stimulation, permanent implantation of the implantable pulse generator is performed.

Jamie Drossaerts and Ranjana Jairam contributed equally to this work.

C 2021 The Author(s)

Published by S. Karger AG, Basel

This is an Open Access article licensed under the Creative Commons Attribution-NonCommercial-4.0 International License (CC BY-NC) (http://www.karger.com/Services/OpenAccessLicense), applicable to the online version of the article only. Usage and distribution for commercial purposes requires written permission.
Correspondence to:

Ranjana Jairam, rjairam89@ hotmail.com 
In 2007, Van Kerrebroeck et al. [1] reported the longterm results of SNM in a multicenter, worldwide clinical trial. Of the implanted patients, $68 \%$ with urgency urinary incontinence, $56 \%$ with urgency frequency (overactive bladder syndrome $[\mathrm{OAB}]$-dry), and $71 \%$ with nonobstructive urinary retention (NOR) had a successful outcome 5 years after initial implantation [1]. In addition, Siegel et al. [2] recently published data from the USA and reported success rates in $\mathrm{OAB}$ patients 5 years after implantation. Of the 340 subjects who completed the test stimulation, 272 had an implant, of which $82 \%$ had a therapeutic success rate at 5 years [2]. A more recent prospective multicenter study evaluated the effectiveness and quality of life (QoL) of patients with OAB or NOR who were treated with SNM and showed a significant improvement of OAB symptoms and QoL during a 10-month follow-up [3].

In order to select the optimal candidates for SNM and to know who will achieve treatment success both in the short and long term, it is crucial to identify factors that can predict the treatment outcome. Although several predictive factors for success in SNM have been identified, the test stimulation has been found to be the only reliable factor in predicting success [4]. Nonetheless, a more reliable selection of patients with highest chance or treatment success (or highest chance of treatment failure) may be improved by identifying additional factors that can predict a successful response. As predictive factors have been the subject of many studies, the goal of this review was to sort out which patient or technical factors potentially could represent a positive or negative prediction for success with SNM therapy (short and long term) in patients with OAB or NOR undergoing SNM test stimulation.

\section{Methods}

This systematic review was registered in PROSPERO under the number CRD42015016256.

\section{Inclusion and Exclusion Criteria}

A literature search for full-length original articles and abstracts was carried out, meeting the following inclusion criteria: (a) adults $\geq 18$ years; (b) diagnosis of refractory OAB; (c) or diagnosis of NOR not satisfied with clean intermittent self-catheterization or problematic clean intermittent self-catheterization, without other treatment options being successful or sufficient; and (d) published in English in a peer-reviewed journal. Primary endpoints were SNM success, both test evaluation and long-term success. Reviews, expert opinions, and comments were excluded. Since the focus of this review is on urinary complaints, we excluded patients with diagnosis of bladder pain syndrome or other pelvic pain. Also, studies regarding nonurinary indications for SNM (i.e., fecal incontinence) were excluded.

\section{Literature Search}

PRISMA guidelines were used concerning preferred reporting items for systematic reviews. The following databases were searched: Medline (PubMed) and Cochrane (RCT). There was no date restriction on the searched articles, and the last search was dated 14 August 2020. MeSH terms, free hand terms and wildcards were used, the detailed query is listed in the online supplementary material (please see www.karger.com/doi/10.1159/000513937). These database searches were supplemented by hand searching the reference lists of eligible articles. Two authors (J.D. and C.d.R.) independently examined titles, abstracts, and full-text articles. Names of authors, institution, and journal of publication were not blinded.

\section{Data Extraction}

Population characteristics such as gender and age of patient groups have been noted, and the results of the study are summarized. The main data items extracted from the articles were study characteristics such as type of study, sample size and methods of recruiting, setting, success rate, and adverse events (AEs). Later, a general classification was made based on all factors that were discussed in the articles: gender, age, duration of complaints, affective symptoms, history of surgery, technical factors, and urodynamics.

Two authors (J.D. and R.J.) independently performed the data extraction. Consensus was obtained in $85 \%$ of the manuscripts; the remaining $15 \%$ of disagreements were handled by discussion. 415 abstracts were identified in the database search, and after removal of duplicates, 437 remained for screening on relevance. In the reference lists, an additional 22 articles were found. Eventually, 156 full-text articles were assessed for eligibility, and 90 articles were excluded resulting in a final set of 67 articles, which were included in this review. Additionally, 11 abstracts published at international meetings were included. Errata would have been examined if articles have been retracted since publication; there were none. A flowchart of the selection process is depicted in Figure 1.

\section{Results}

\section{Quality Assessment of the Included Literature}

Level of evidence was stated per article as defined in publications of the University of Oxfords' Centre for Evidence-Based Medicine (CEBM) [5]. Risk of bias assessment was performed according to the Cochrane Collaboration guidelines (Table 1) [6].

Most articles described cohort study designs (70\%). The remainder were case series and randomized controlled trials (25 and 5\%, respectively). In most studies, primary outcome was a successful SNM test result defined as a $\geq 50 \%$ improvement in urinary symptoms. In 34 studies, test stimulation success was the main outcome [7-40]. In 19 studies, both test stimulation outcome and permanent SNM outcome were investigated [41-59]. In 14 studies, only permanent SNM outcome was investigated [60-73].

In 15 studies, a percutaneous nerve evaluation (PNE) was performed and in 23, a tined lead procedure (TLP). In 19 studies, patients underwent either PNE or TLP. In 
Fig. 1. Flowchart of selection process according to the PRISMA guidelines.

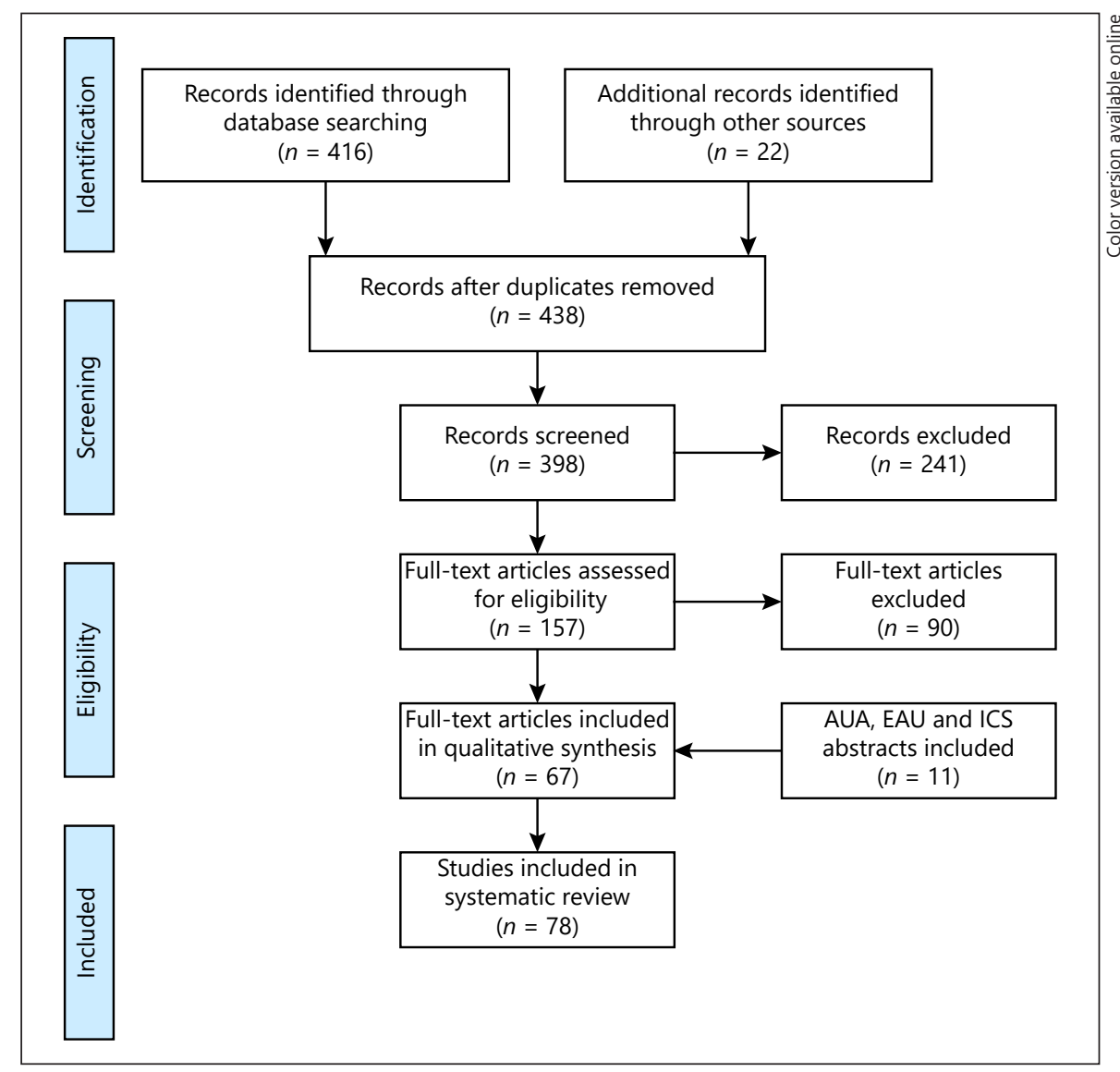

3 studies, it was unknown which procedure was used (Table 2). In most articles, risk of bias domains was assessed as low risk or unclear risk (Fig. 2). A graphical summary of the results is depicted in Figure 3.

Gender

Fifteen studies investigated gender as a predictive factor in SNM outcome [7, 10, 13, 19, 23, 26, 27, 30, 37, 38, $45,49,63,64,69]$. In 9 studies, the patient population was heterogeneous with both $\mathrm{OAB}$ and NOR patients $[10,23$, $26,30,38,45,49,64,69]$. Four out of 10 studies reported a higher chance of successful test stimulation in females in a mixed group of OAB and NOR patients [10, 23, 27, 49]. However, 2 of these studies were conducted in the same study population $[10,23]$. Three studies found less successful test stimulation outcomes in men: in one study, only in patients with NOR $[7,13,38]$. In 5 studies, gender did was not predictive in successful test stimulation outcome $[19,26,30,37,45]$.

Three studies reported on permanent SNM and found gender not to be a predictive factor $[63,64,69]$. Two of these studies included a heterogeneous group of patients with either $\mathrm{OAB}$ or $\mathrm{NOR}$, and 1 study reported AEs at follow-up.

Age

Several studies reported on age as a predictive factor for SNM test success. In total, 32 studies and 4 abstracts were included $[7,8,10,13,16,19,21-24,26,30,31,34$, $37-39,43,45,49,52,55-60,62,63,67,68,72,74-77]$.

Overactive Bladder Syndrome

Twelve studies investigated age as a predictive factor in patients with $\mathrm{OAB}[8,21,22,31,34,37,43,56,57,62$, $63,72]$. Five of these studies included only women $[21,34$, $56,57,72]$. Two of these found younger age to be predictive in successful test stimulation outcome [21] and longterm outcome [57]. Eight studies reported on successful test stimulation of which 3 found a younger age predictive in successful test stimulation $[8,21,22,31,34,37,43,56]$. In 2 other studies, age was not predictive in neither successful test stimulation nor successful treatment with the implant $[62,63]$. 


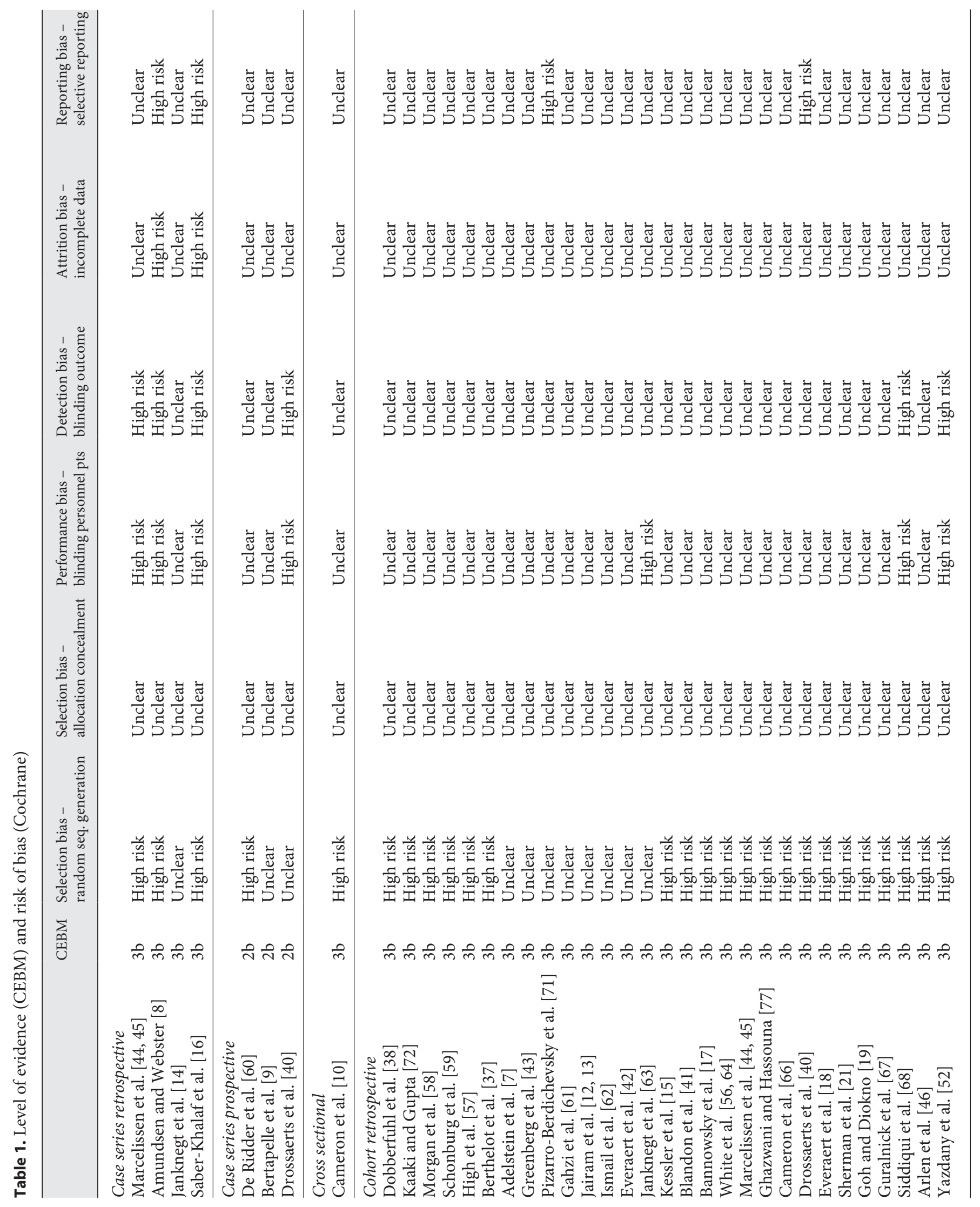




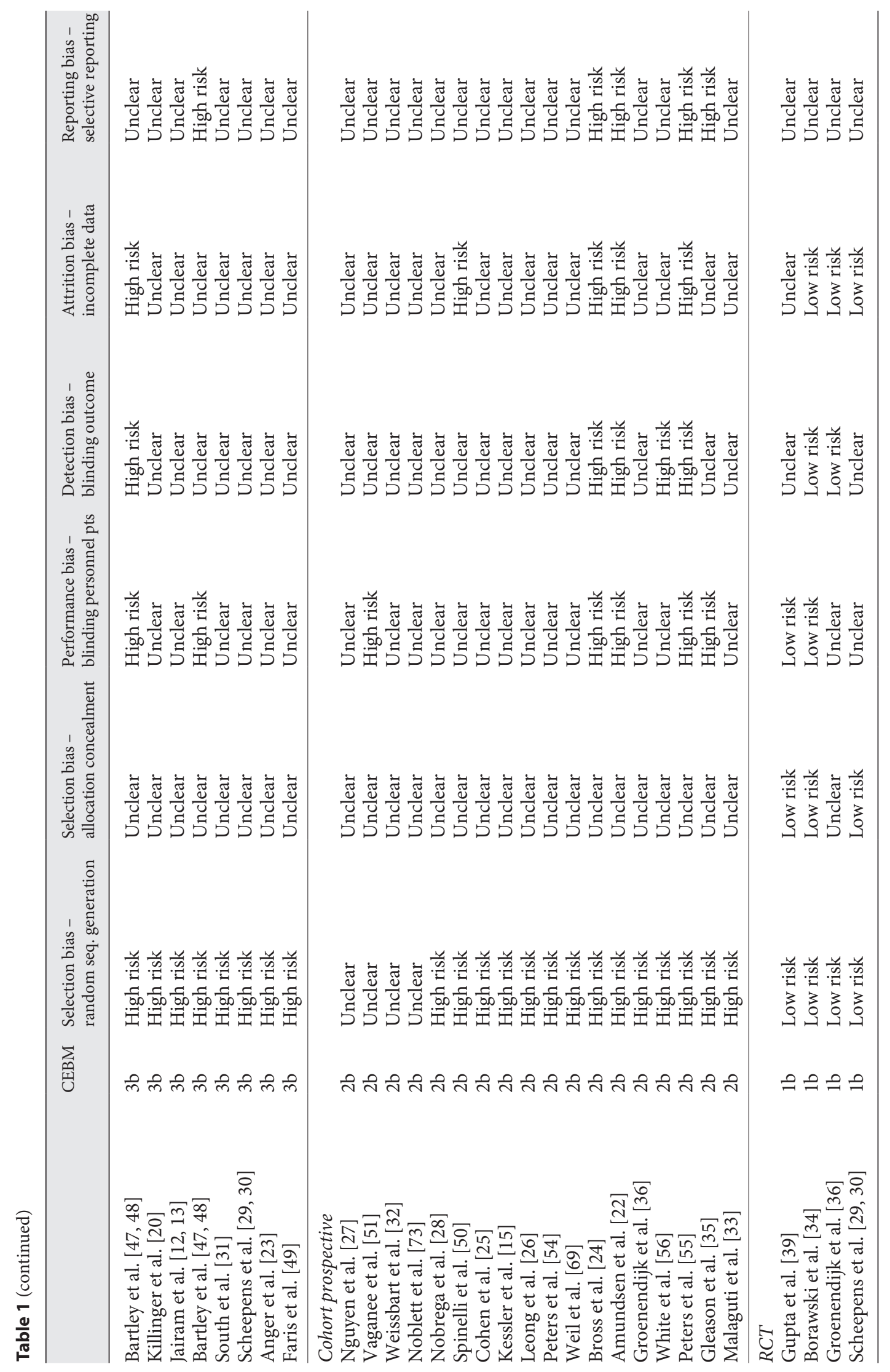




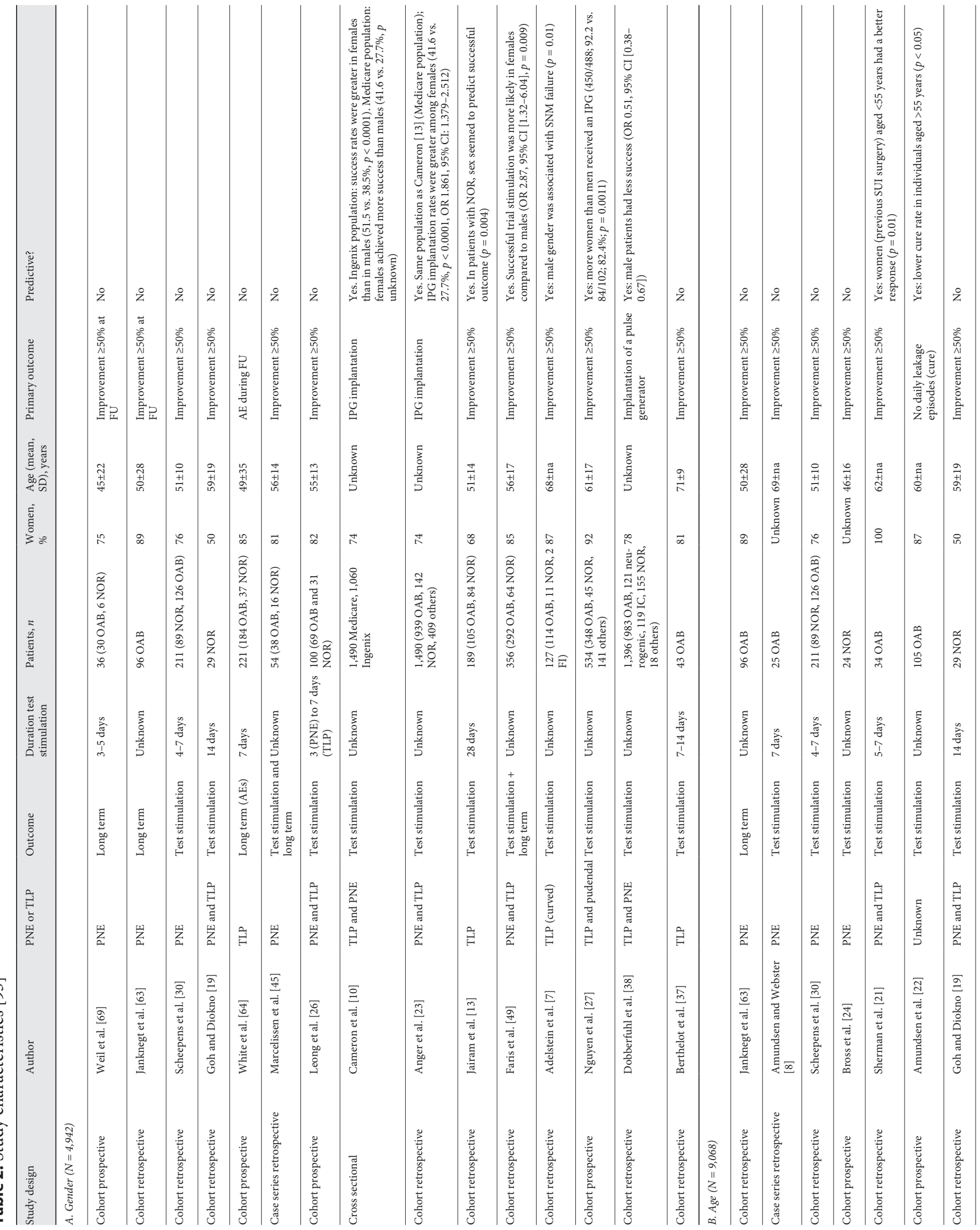




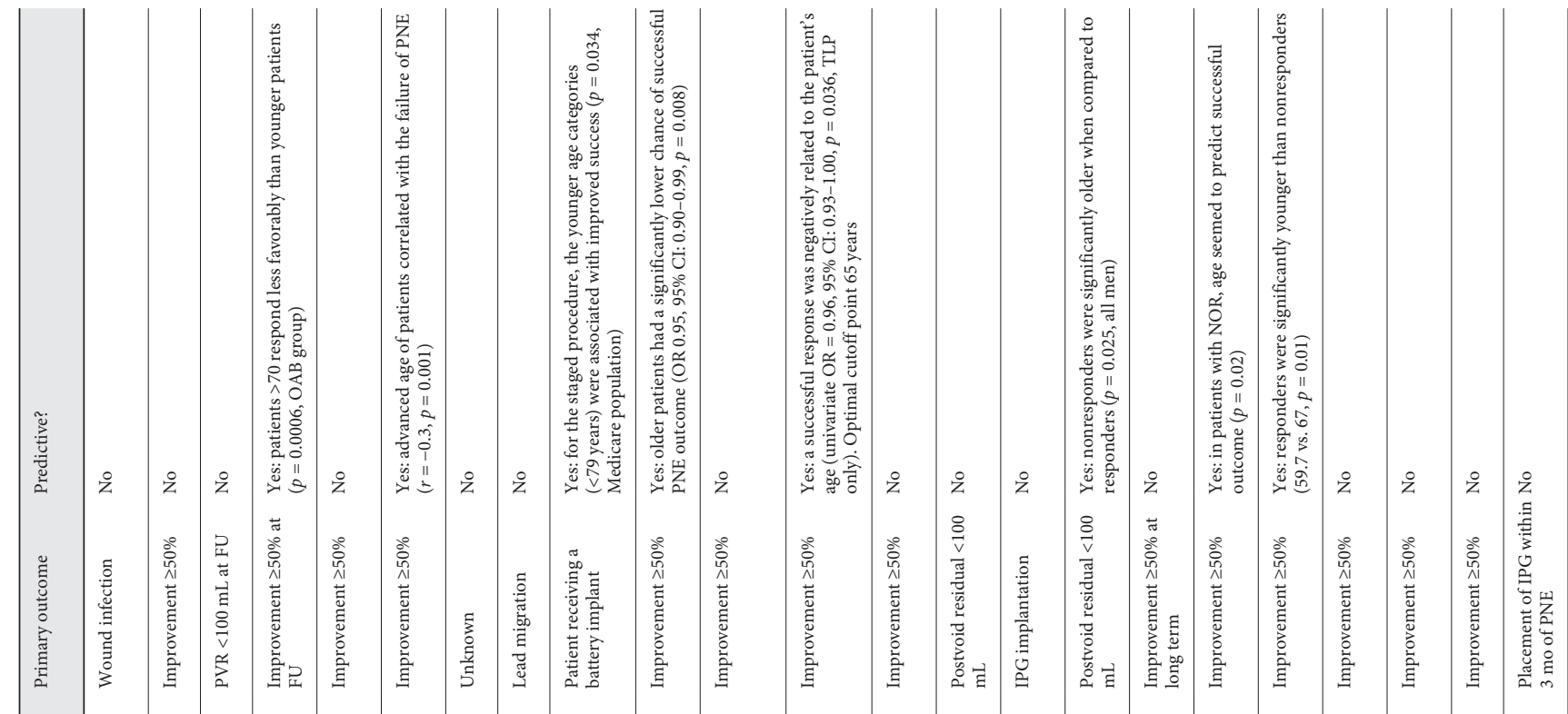

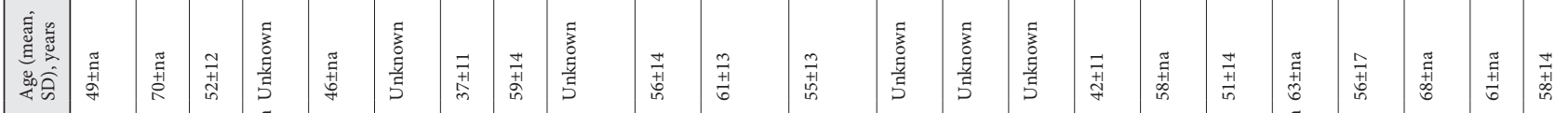

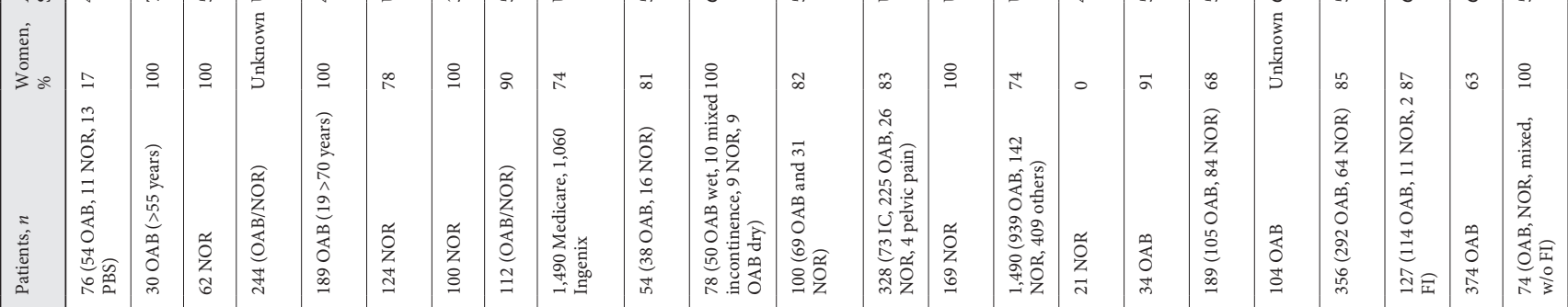

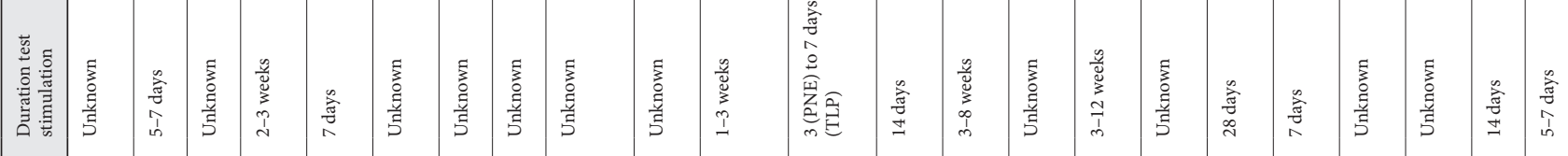

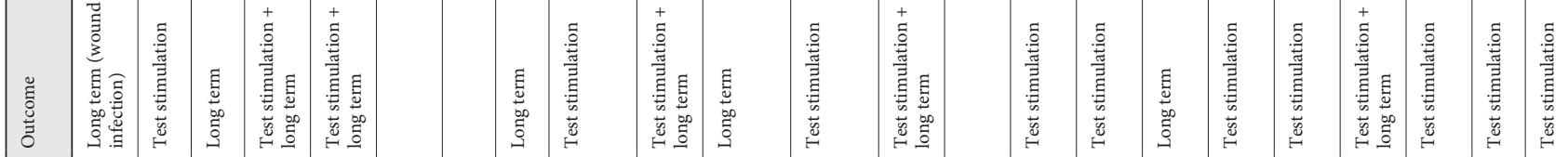

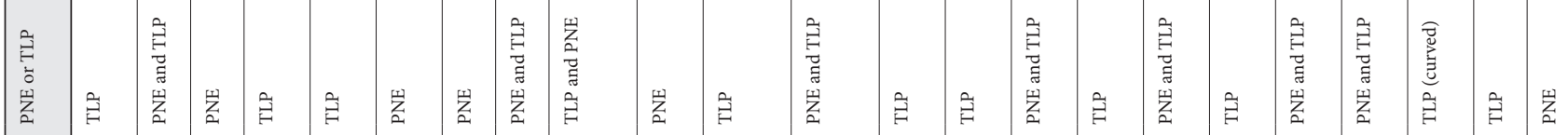

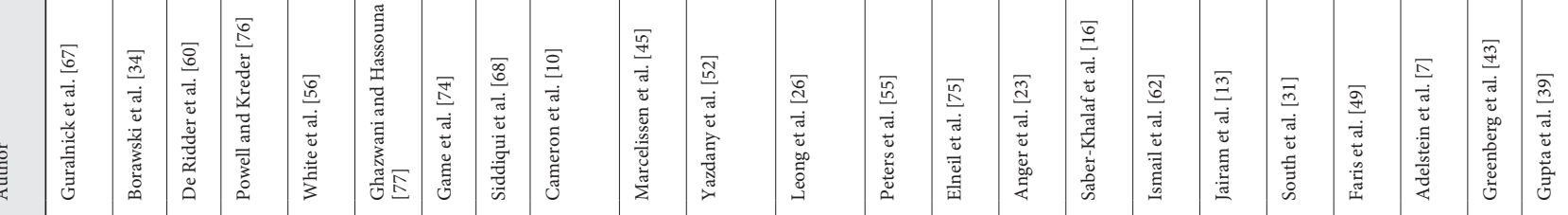




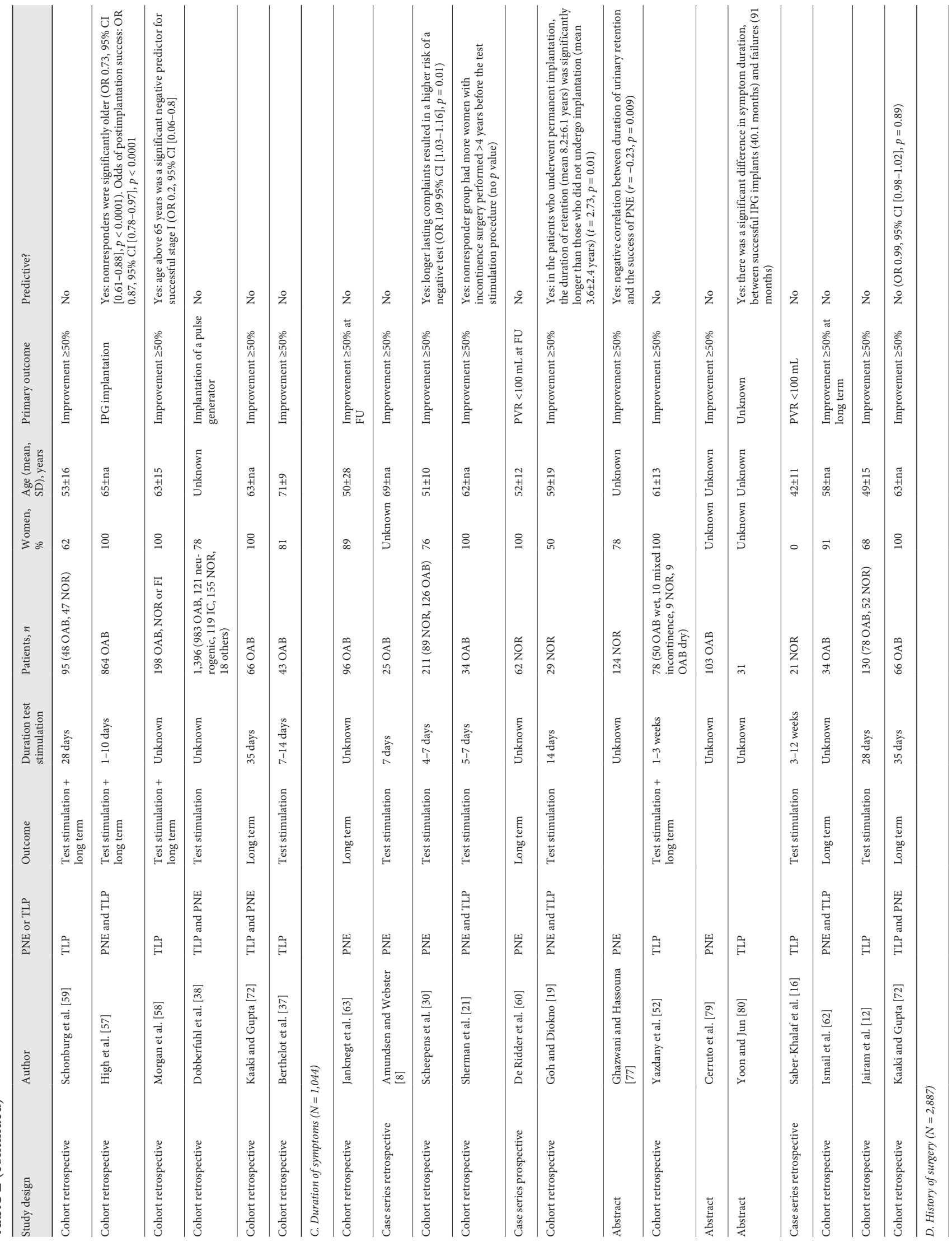




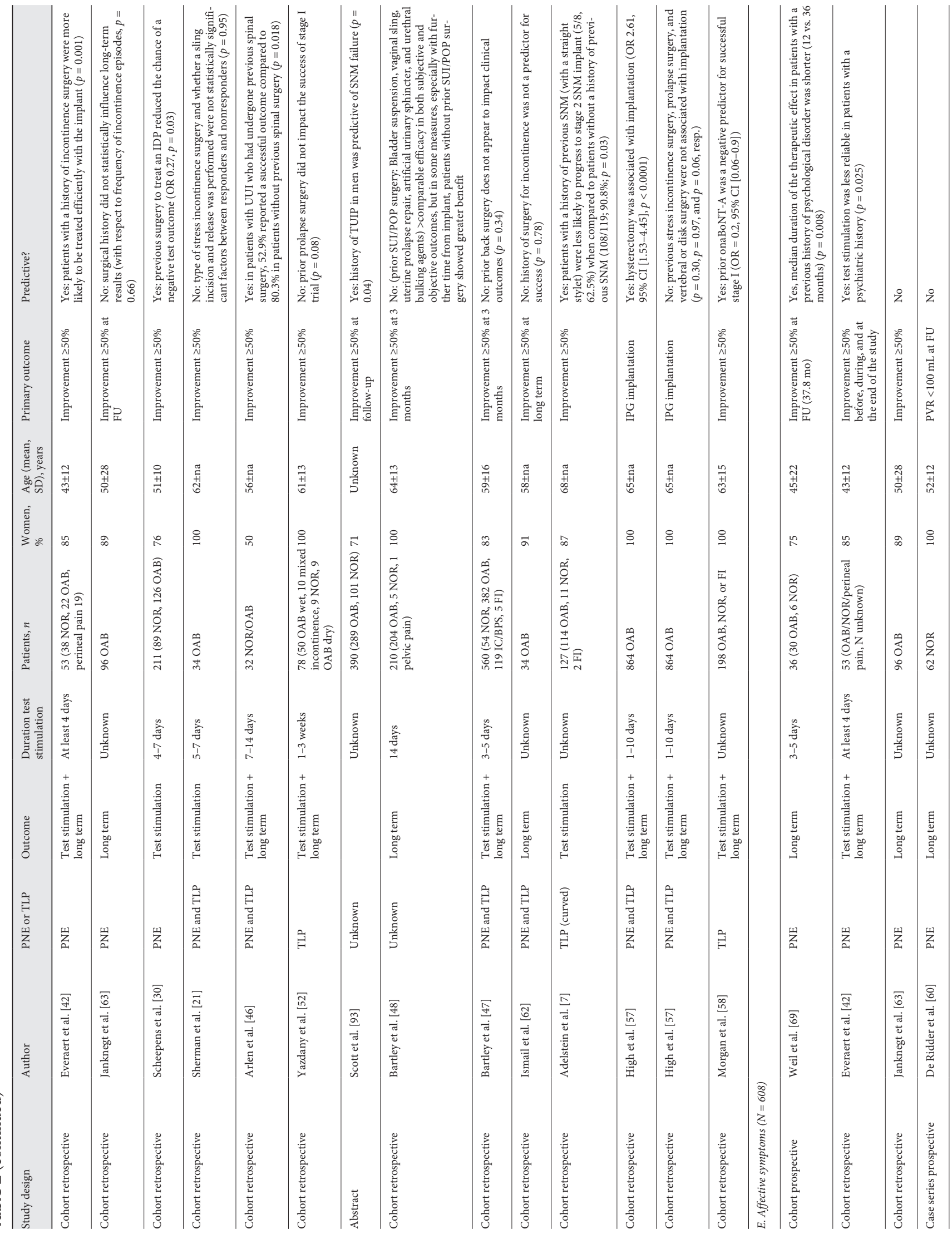




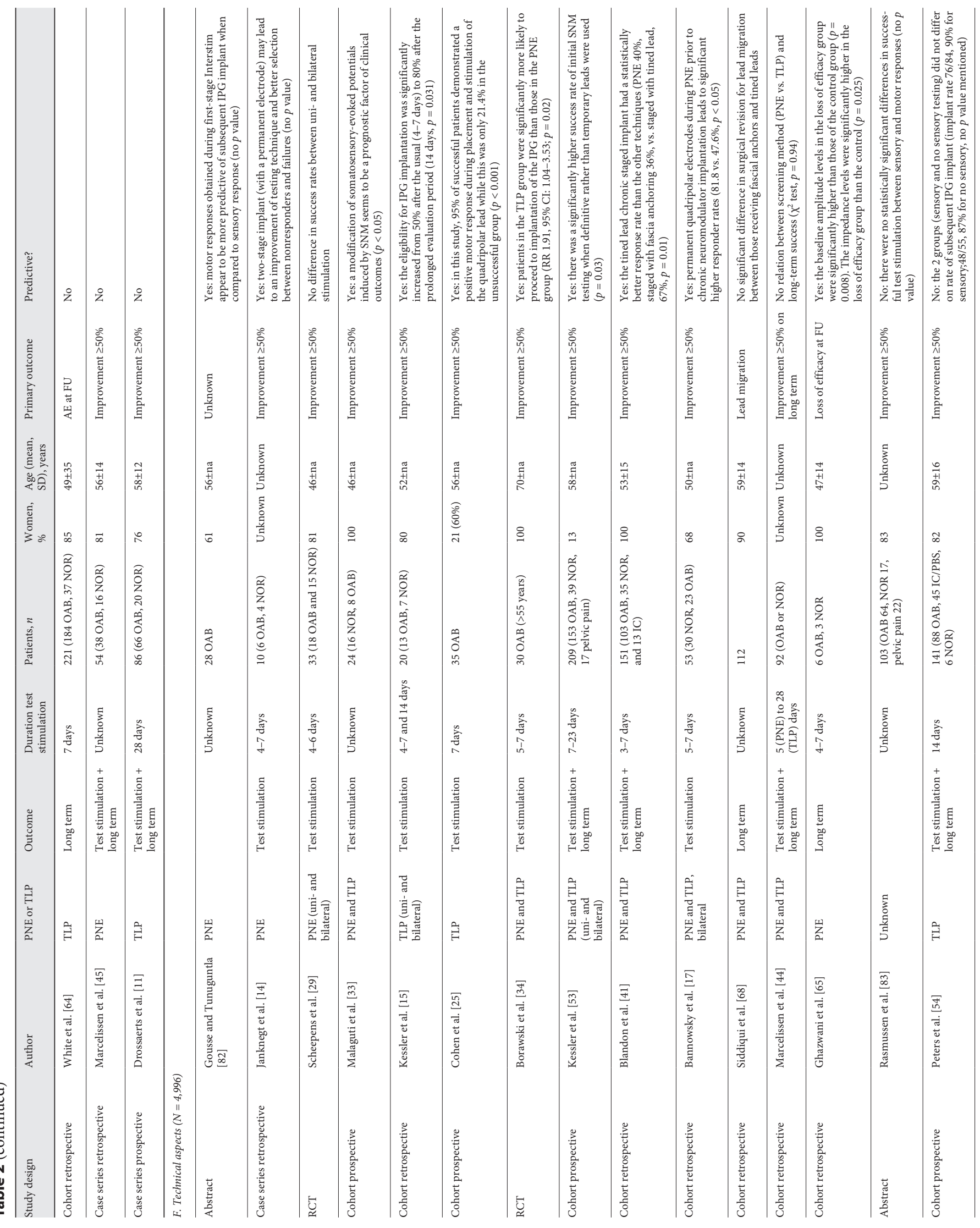




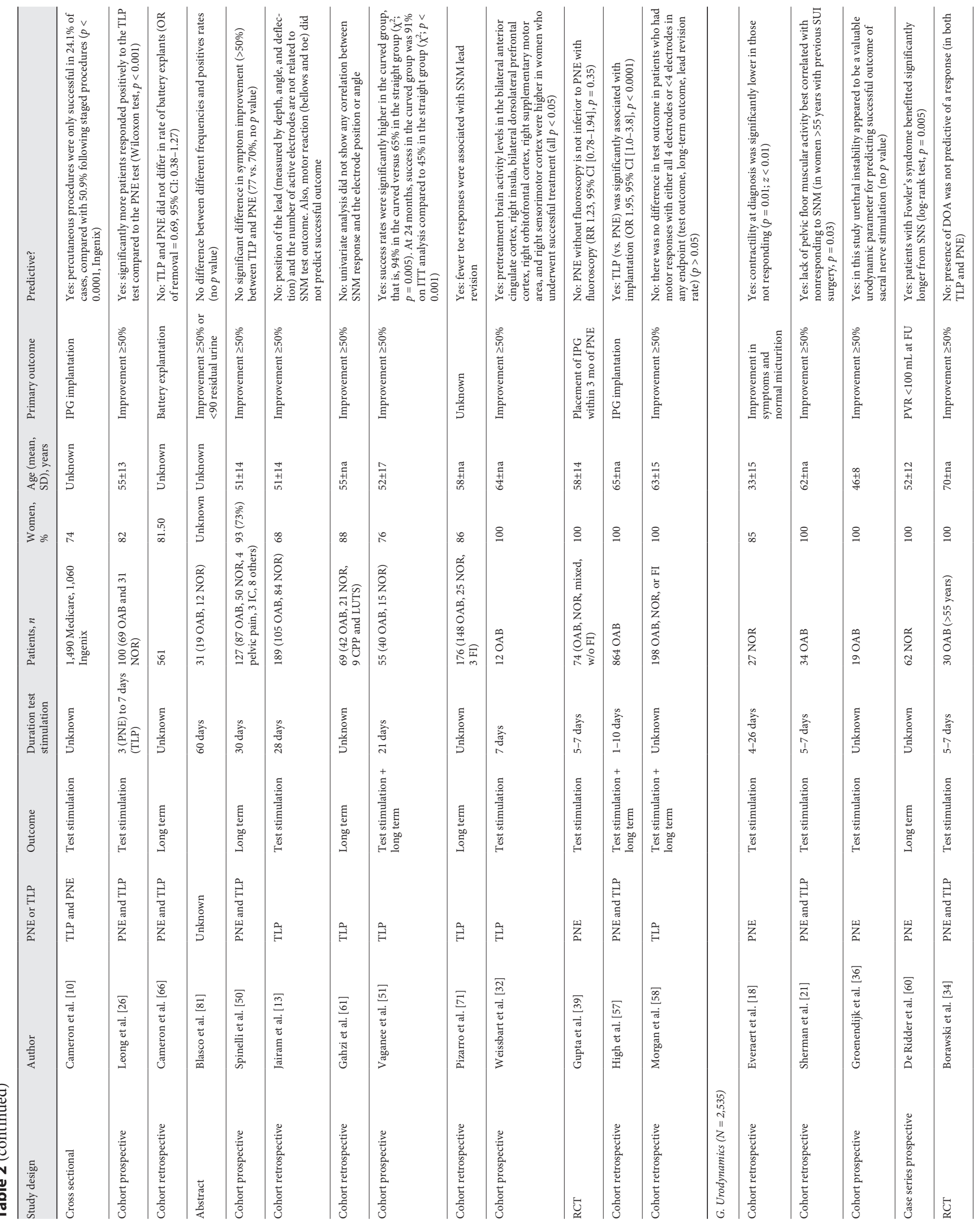




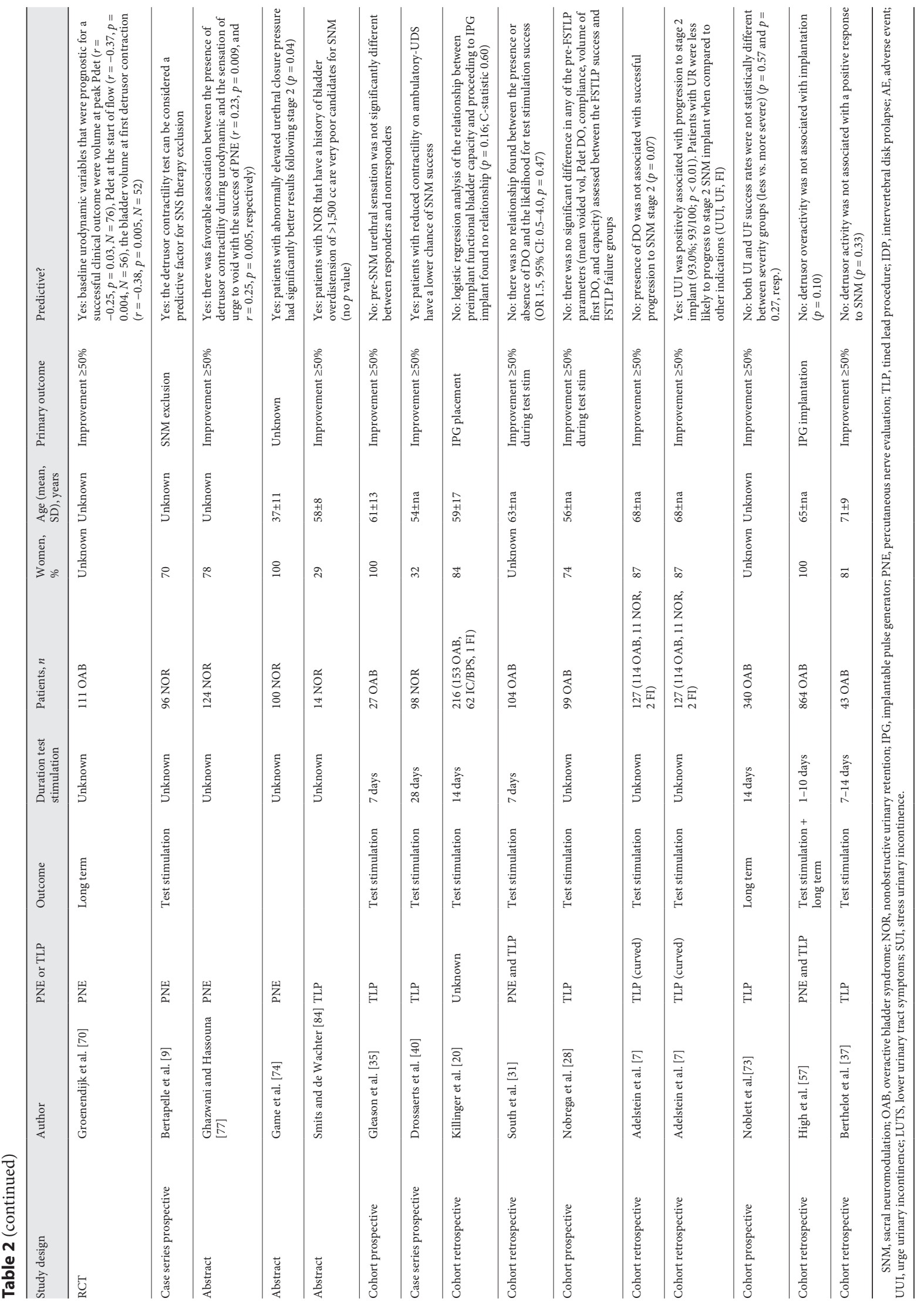


Fig. 2. Risk of bias assessment (Cochrane).

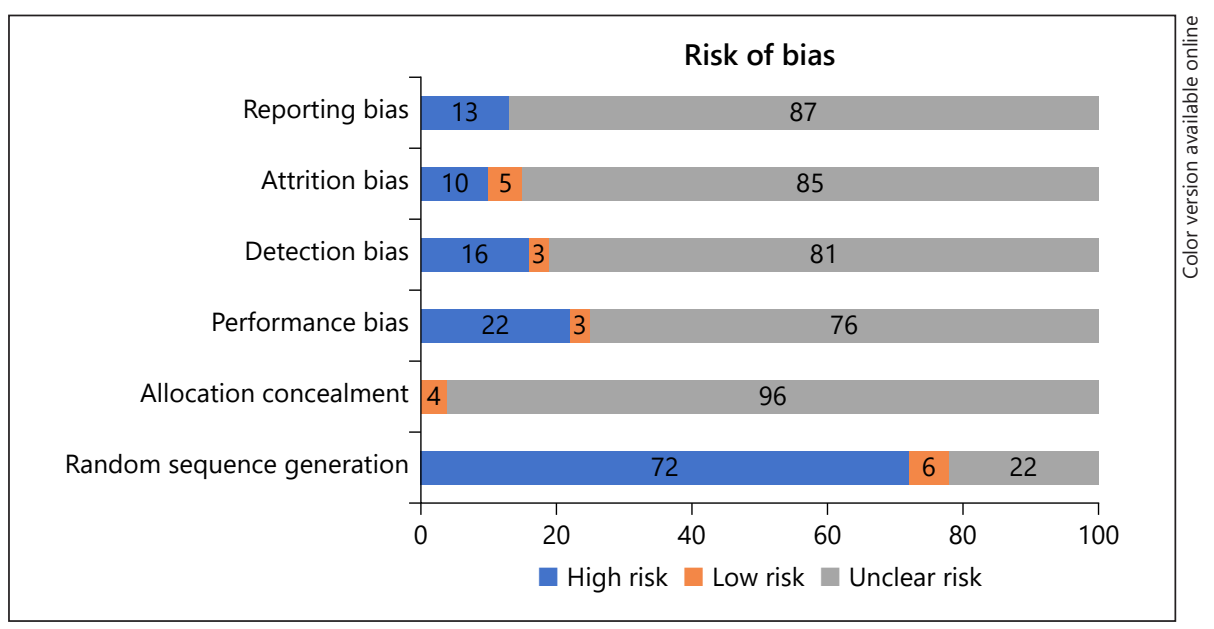

Nonobstructive Urinary Retention

Four studies and 3 abstracts included patients with NOR $[16,19,24,60,74,75,77]$. Three studies reported on successful test stimulation of which one consisted of only men and reported that nonresponders were significantly older when compared to responders [16]. One study reported on successful treatment at follow-up and found age not to be predictive [60]. Furthermore, 1 abstract concluded that advanced age was correlated with failure of PNE test stimulation [77].

\section{$\mathrm{OAB}$ and NOR}

Twelve studies and 1 abstract reported on successful test stimulation outcome $[7,13,23,26,38,39,45,49,55$, $59,68,76,78]$ of which 6 studies also reported on longterm outcome $[45,49,55,58,59,76]$. Marcelissen et al. [45] investigated predictive factors for test stimulation outcome and AEs at long-term follow-up. They found younger age ( $<65$ years) to be a predictor in successful PNE test stimulation, but this was not seen for the occurrence of AEs at follow-up [45]. Leong et al. [26] also found younger age to be predictive in successful test stimulation. However, this was only seen in patients who received TLP, and they did not report long-term outcomes.

\section{Duration of Symptoms}

In total, 11 studies and 3 abstracts were included $[8,12$, $16,19,21,30,52,60,62,63,72,77,79,80]$. These studies consist of small groups of patients who had complaints for only a couple of years.

Overactive Bladder Syndrome

Six studies reported on patients with $\mathrm{OAB}[8,21,62$, $63,72,79]$. Two of these reported on outcome after test stimulation $[8,21]$ of which one found a shorter duration of complaints to be successful in test stimulation outcome [21]. In this study, women who developed $O A B$ after stress incontinence surgery were included. They found that a test stimulation performed within 4 years of the stress incontinence procedure was positive in predicting successful test stimulation. The other 4 studies (of which one was an abstract) did not find duration of complaints to be predictive in successful treatment with SNM on long term $[62,63,72,79]$.

\section{Nonobstructive Urinary Retention}

Regarding NOR patients, 3 studies and 1 abstract were included $[16,19,60,77]$. Two studies reported on successful test stimulation $[16,19]$. One found a longer duration of retention to be a negative predictor in successful test stimulation [19]. Furthermore, an abstract of Ghazwani and Hassouna [77] found a negative correlation between duration of retention and a successful PNE test. One other reported on successful outcome on long term and did not find duration of complaints to be predictive [60].

\section{$\mathrm{OAB} / \mathrm{NOR}$}

Three studies and 1 abstract consisted of patients with either OAB or NOR $[12,30,52,80]$. All reported on successful test stimulation, and 2 studies found that longer lasting complaints resulted in a higher risk of a negative test stimulation $[30,80]$.

\section{History of Surgery}

Ten studies reported on prior spinal back surgery and/ or abdominal surgery [21, 30, 42, 46-48, 52, 57, 62, 63], one study on previous SNM surgery [7], and one on pre- 
Gender as a positive predictor for SNM success (test stimulation and/or long-term). No study found male gender to be a positive predictor.

Gender (15 studies)

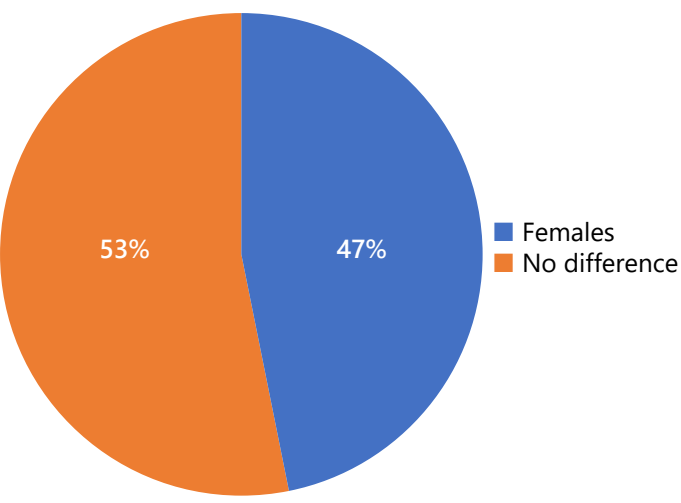

a

Duration of complaints as a negative predictor for SNM success (test stimulation and/or long-term). No study found shorter duration to be a negative predictor.

Duration of complaints (14 studies)

C

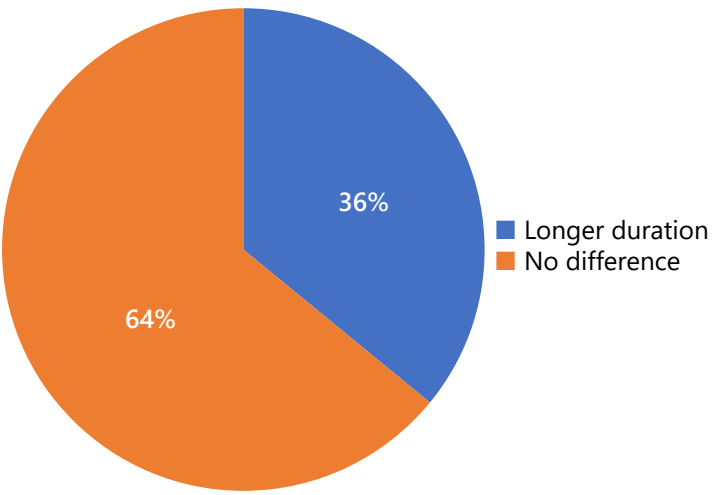

Age as a positive predictor for SNM success (test stimulation and/or long-term). No definition of younger age could be made.

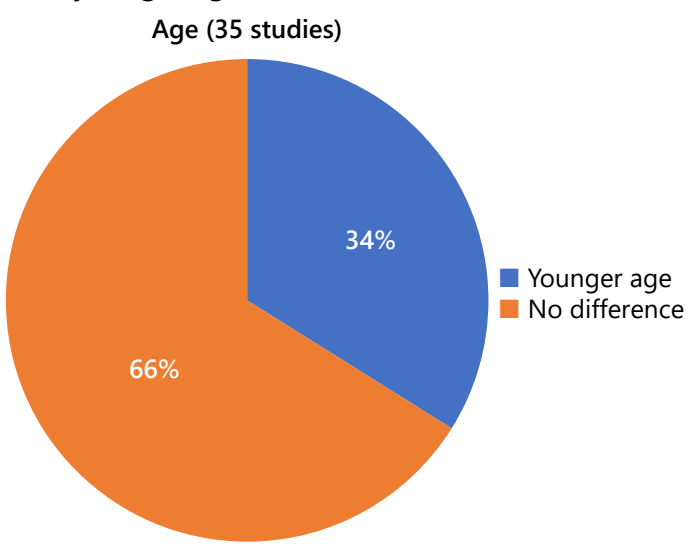

Affective symptoms as a negative predictor for SNM success (test stimulation and/or long term). No study found affective symptoms to be a positive predictor. Affective symptoms (7 studies)

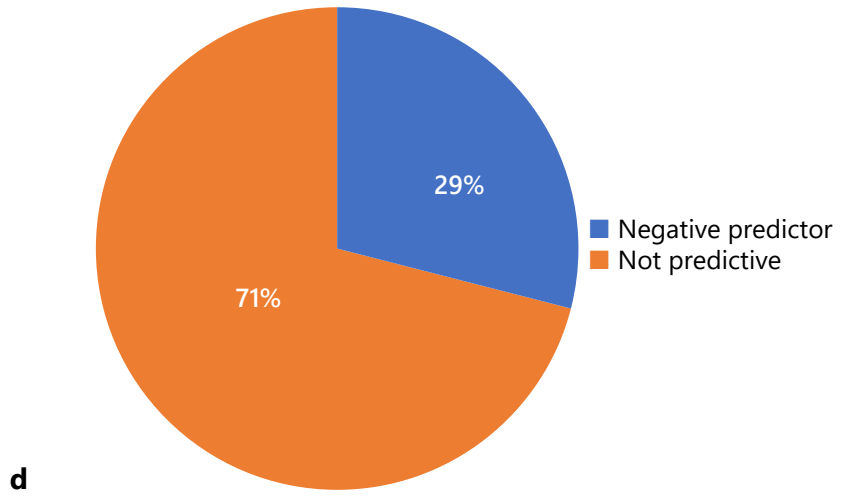

Factors related to surgical history with the number of studies per factor and the outcome (in percentage)

History of surgery (15 studies)

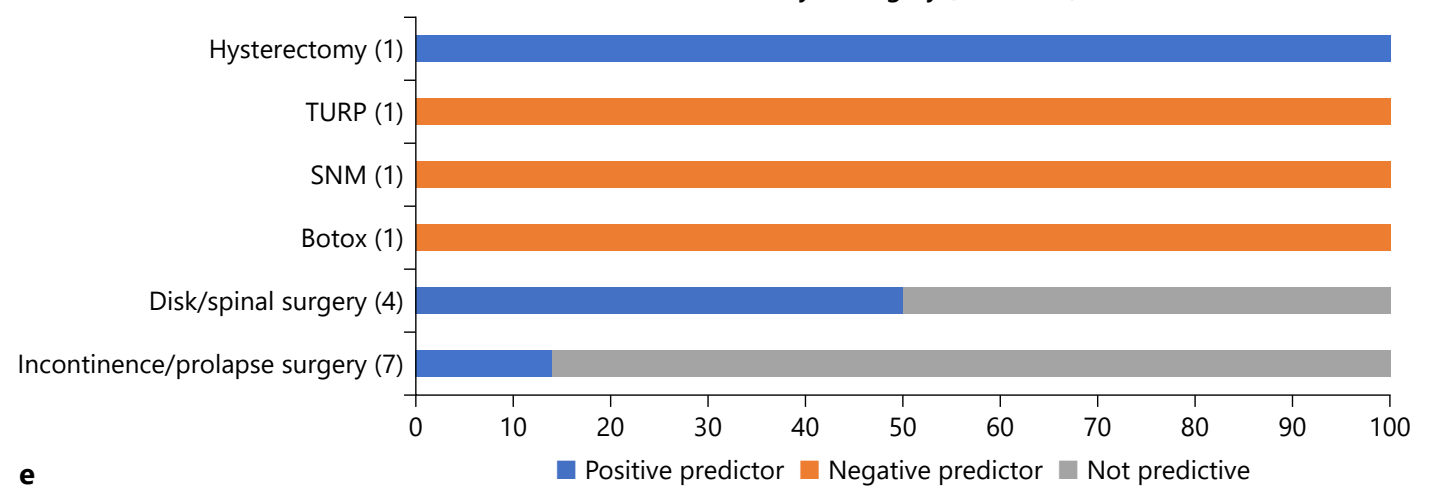

3

(Figure continued on next page.)

Jairam/Drossaerts/Marcelissen/van Koeveringe/Vrijens/van Kerrebroeck 
Fig. 3. a-g Graphical summary of the result. SNM, sacral neuromodulation; PNE, percutaneous nerve evaluation; TLP, tined lead procedure; UUI, urge urinary incontinence.

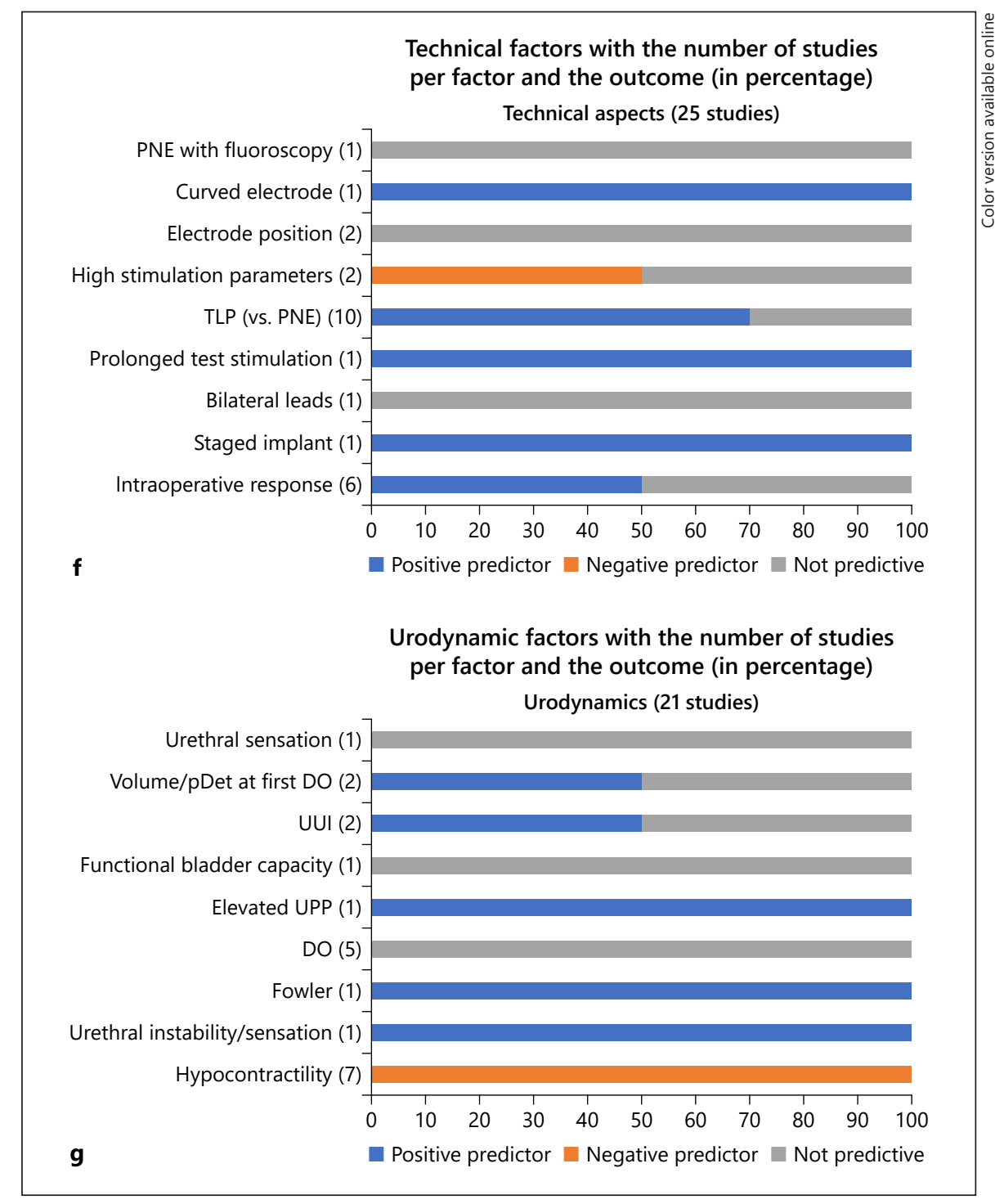

vious treatment with onaBoNT-A [58]. One abstract reported on previous TUIP in men undergoing SNM.

Overactive Bladder Syndrome

Four studies included patients with refractory urinary urgency incontinence $[21,57,62,63]$. All reported on test stimulation success and 2 also on success on long term. Sherman et al. [21] evaluated the response to SNM in women with refractory, urinary urgency incontinence after stress incontinence surgery. They found no difference between responders and nonresponders with respect to type of stress incontinence surgery [21]. Janknegt et al. [63] studied long-term effectiveness of SNM in 96 patients with $\mathrm{OAB}$. Prior to study enrollment, these patients underwent 177 surgical procedures for the treatment of

Is Success in Sacral Neuromodulation Predictable? urinary problems. Surgical history did not appear to statistically influence the long-term results [63]. Furthermore, Ismail et al. [62] assessed functional outcomes of SNM in 34 patients with a median follow-up of 9.7 years. They did not find a history of incontinence surgery (i.e., sling, artificial urinary sphincter, and colpopexy) to be predictive in long-term outcome. High et al. [57] found previous hysterectomy to be associated with implantation while previous stress incontinence surgery, prolapse surgery, and vertebral or disk surgery were not associated with implantation.

\section{$\mathrm{OAB} / \mathrm{NOR}$}

The remaining 8 studies and 1 abstract consisted of a heterogeneous group of patients. In 3 studies, patients 
had undergone back surgery for different indications prior to SNM test stimulation [30, 46, 47]. Arlen et al. [46] investigated a group of patients with $\mathrm{OAB}$ or NOR who had undergone previous spinal cord surgery. The most common indication for spinal cord surgery was disk disease. The authors conclude that patients with voiding dysfunction (OAB or NOR) following spinal surgery can be treated successfully with SNM, but success is less likely in patients suffering from urgency incontinence [46]. This is in contrast to the results of Scheepens et al. [30] who investigated several factors and found intervertebral disk prolapse surgery to be a positive predictor of SNM test success. Another study from Bartley et al. [47] included 560 patients of which 109 had prior back surgery. Indication for back surgery was only clear in 25 patients (bulging disk, spinal stenosis, trauma, and osteoarthritis). Regarding test stimulation and follow-up with the implant (2.3 years), prior back surgery did not appear to impact clinical outcomes [47].

A study of Everaert et al. [42] investigated success rate and complications in 53 patients and found that patients with a history of incontinence surgery were more likely to be treated efficiently with the implant. Previous onaBoNT-A was studied in 1 study and was a negative predictor for successful implantation [58].

\section{Affective Symptoms}

In total, 7 studies evaluated affective symptoms as a predictive factor $[11,42,45,60,63,64,69]$. In 3 of these studies, the authors studied the presence of psychological factors prior to test stimulation as primary outcome and found no significant relationship between psychiatric history and SNM outcome $[11,45,60]$. In these 3 studies, several questionnaires were used as a screening tool (SCL90-R, PHQ, and HADS). In the other 4 studies, psychological factors were less well defined, and patients were not screened for psychological factors prior to test stimulation $[42,63,64,69]$.

Overactive Bladder Syndrome

A study of Janknegt et al. [63] concluded that a psychiatric history in $96 \mathrm{OAB}$ patients did not influence the long-term effectiveness with respect to the frequency of incontinent episodes.

\section{Nonobstructive Urinary Retention}

One study investigated whether psychologic preimplant screening was predictive in long-term success women with urinary retention. They used the Patient Health Questionnaire as psychologic preimplant screening and concluded that it did not correlate with long-term outcome [60].

\section{$\mathrm{OAB} / \mathrm{NOR}$}

In 5 studies, a heterogeneous group of patients was investigated [11, 42, 45, 64, 69]. In 1 study, a difference in outcome between the test stimulation and implantation was significantly related to psychiatric disease in the history [42]. Another study of Marcelissen et al. [45] showed no relationship between psychological characteristics (measured by ABQ or SCL-90-R questionnaires) and both test and long-term outcome. However, a psychiatric history was found to be a positive predictor for the occurrence of $\mathrm{AE}$ with permanent SNM treatment. A study of Weil et al. [69] showed that patients with a previous history of psychological disorder had a lower median duration of therapeutic effect at follow-up.

\section{Technical Procedure}

Regarding the technical procedure, several articles were included. In total, 22 studies and 3 abstracts investigated whether technical aspects can predict SNM outcome $[10,13-15,17,25,26,29,32-34,41,44,50,51,53$, $54,61,65,66,68,71,81-83]$. Factors that were studied were type of procedure/lead, length of test stimulation, intraoperative testing, and postoperative stimulation parameters. Four studies involved bilateral placed leads [15, $17,29,53]$. One of these was a randomized trial where the clinical effect of temporary unilateral versus bilateral stimulation was compared in a mixed group of $O A B$ and NOR patients. Significant differences in test stimulation outcome in unilateral versus bilateral stimulation could not be demonstrated [29].

\section{Motor versus Sensory Response}

One abstract and 1 study investigated whether intraoperative motor or sensory response is more predictive of successful test stimulation in patients with $\mathrm{OAB}[25,82]$. The authors found that a positive test stimulation is more likely when intraoperative lead placement results in positive motor response versus only sensory response. This is in contrast to what 2 others found in a mixed group of $\mathrm{OAB}$ and NOR patients. Peters et al. [54] performed a prospective study and found no difference in implantable pulse generator implantation rate or clinical outcome at follow-up. An abstract of Rasmussen et al. [83] retrospectively reviewed their results for a successful test stimulation in 103 patients of which 67 had bilateral leads. They did not find a statistically significant difference between sensory and motor responses [83]. Furthermore, Pizarro- 
Berdichevsky et al. [71] found that fewer toe responses (on each contact point) were associated with lead revision; however, no association between motor response (bellows and toe) and successful test stimulation was found. This is in line with the results by Morgan et al. [58] who also found no difference in test outcome and longterm outcome between patients who had a motor response on all 4 contact points versus $<4$ contact points.

Type of Procedure/Lead

Three studies investigated whether a permanent lead (i.e., used during test stimulation) resulted in better test stimulation outcome in a mixed group of $\mathrm{OAB}$ and $\mathrm{NOR}$ patients. Janknegt et al. [63] implanted a permanent electrode (which was fixed to the sacrum) in 10 patients who failed a previous PNE test. Eighty percent showed a successful test stimulation and received a definitive implant. These results are in line with 2 other studies where a permanent electrode (either fixed to the sacrum or tined) showed more successful test stimulation outcome [17, 53]. Regarding lead migration, Siddiqui et al. [68] did not find a significant difference between the amount of revisions in patients who received fascial anchors and tined leads. Vaganee et al. [51] reported significantly higher success rates in both test stimulation and at long-term follow-up when patients received a curved tined lead, when compared to patients who received a straight tined lead.

Several studies investigated test stimulation success rates in $\mathrm{OAB}$ and NOR patients and reported a higher success rate in patients who received TLP when compared to patients who received PNE [10, 26, 34, 41, 57]. Marcelissen et al. [44] investigated 92 patients with $\mathrm{OAB}$ or NOR who received either TLP or PNE and found no significant difference in long-term success between the 2 groups. Furthermore, another study of Kessler et al. [15] stated the prolonged testing using permanent (quadripolar) leads is more reliable for accurate patient selection than the evaluation period of 4-7 days.

Intraoperative Testing and Positioning Lead

Two studies investigated whether the position of the electrode in the sacral foramen predicted test stimulation success or permanent SNM success [13, 61]. None found any correlation between the position (depth, angle, and deflection) and test and long-term success. Loss of efficacy was associated with high stimulation parameters at time of implantation in 1 study [65]. Furthermore, 1 RCT found PNE without fluoroscopy was not inferior to PNE with fluoroscopy [39].

Is Success in Sacral Neuromodulation Predictable?

\section{Urodynamic Parameters}

In total, 16 studies and 3 abstracts investigated urodynamic parameters in patients prior to test stimulation [7, $9,18,20,21,28,31,34-37,40,57,60,70,73,74,77,84]$.

\section{Detrusor Contractility}

Three studies and 2 abstracts found that NOR patients with a reduced detrusor contractility had a lower chance of successful test stimulation $[9,18,40,77,84]$. Furthermore, De Ridder et al. [60] concluded that patients with Fowler's syndrome benefitted significantly longer from SNM when compared to patients with idiopathic retention.

\section{Detrusor Overactivity}

Seven studies confirmed that the presence of detrusor overactivity was not correlated with successful test stimulation $[7,28,31,34,37,57,70]$.

\section{Others}

Two studies reported whether primary indication affects successful conversion to implantation. Adelstein et al. [7] retrospectively reviewed their data of 127 patients with $\mathrm{OAB}, \mathrm{NOR}$, or fecal incontinence undergoing firststage SNM. All patients were tested with a curved lead. They found a positive association between urge urinary incontinence and progression to a definitive implant. Furthermore, they also found that patients with NOR were less likely to receive a definitive implant [7].

A study of Noblett et al. [73] found that success rates (at 12 and 24 months after implantation) between patients with less severe and more severe UI and/or UF symptoms did not statistically differ.

\section{Discussion}

Currently, the only reliable predictor for treatment success in SNM is test stimulation. Although various studies have evaluated predictive factors in patients with $\mathrm{OAB}$ or NOR, no consistent factors have been identified that can be used as an absolute selection criterion in clinical practice.

The studies that were included in this review are heterogeneous which makes it difficult to comprehend the results and to form a general consensus on predictive factors of SNM success. Also, primary outcome among the studies was different: some studies focused on AEs at follow-up, others reported on patient-reported outcome, and some evaluated outcome with voiding diaries. 
Several studies showed that patients with younger age and female gender tend to be more successful in SNM. The decrease in success rates in males over females may be due to the complex voiding dysfunction in men partially owing to the influence of prostatic obstruction. There are no studies that confirm this statement. A possible explanation for a reduced success rate among older patients could be that they may have subtle changes in the bladder and neural control systems for the bladder. However, in most studies, age did not predict successful outcome on the long term.

Several urodynamic parameters have been studied in order to find predictive factors. The presence of $\mathrm{DO}$ in patients with $\mathrm{OAB}$ did not seem to be a negative predictor according to several studies. Furthermore, an acontractile detrusor was found to reduce success rate in patients with NOR considerably $[77,84]$. Most probably, a preserved detrusor contraction is obligatory, since SNM exerts its beneficial effect mainly via relaxing the pelvic floor and the external urethral sphincter rather than via direct stimulation of the contraction of the detrusor muscle. However, there are no studies that confirm this statement.

After the introduction of the tined lead, studies reported success rates with the use of a tined lead in patients who initially failed PNE $[14,44]$. Interestingly, test stimulation with TLP did not seem to be an independent predictor for success on the long term [44]. It seems that regarding test outcome, TLP provides a better patient selection when compared to PNE, but once implanted, no difference is seen in long-term outcome. Regarding type of lead, a prospective study with a 2-year follow-up showed that the use of a curved stylet was found to be a positive predictor for test success [51]. Even though there is only one study concluding this, the curved lead follows the curvilinear route of the sacral nerve roots which should result in a more precise position of the lead. A randomized prospective crossover study showing lower amplitudes with a curved stylet confirms this statement [85]. The authors did not investigate implantation rates, but most probably, a curved lead will lead to a higher success rate. Another technical aspect such as the presence of perioperative motor response was found to be a positive predictor for a successful test stimulation. A possible reason for this outcome could be that the motor response is more beneficial than a sensory perception since these muscle groups are innervated by the same nerves as those involved in improving urinary control in overactive bladder and refractory urgency incontinence. However, after implantation, patients rely on the sensation to ensure continuity of pelvic neuromodulation. This means that the sensory perception of the sacral afferent component plays an important role in the course of SNM. During test stimulation, preferably both motor and sensory responses should be considered since neither of the 2 alone can predict successful outcome.

Several studies report a negative impact of lower urinary tract symptoms in general on QoL and on mental health [86, 87]. Also, in the literature, an association is described between the overactive bladder and the presence of affective symptoms $[88,89]$. Recent studies show that affective symptoms do not predict SNM outcome (both test stimulation and long term) [45, 60, 63]. The primary outcome of the studies included in this review was not homogeneous, which makes it difficult to compare these results.

In our review, most studies did not find a longer duration of complaints to be predictive in test outcome and long-term outcome. Most probably, SNM facilitates restoration of structural changes that can occur in the untreated, underactive, and overactive bladder or allows to compensate [90]. One study stated that SNM restores the sensory and motor neural pathways of the lower urinary tract and that if a disorder is present for a longer time, restoration of the natural equilibrium (i.e., the normal balance) between the different reflexes is more difficult [30]. Since there are no studies that confirm this statement, in our opinion, SNM remains a feasible treatment option in patients with both long and short duration of complaints.

Studies investigating prior back surgery or stress urinary incontinence (SUI) surgery as a predictive factor expect neurological impairment on local level (bladder) or more central (spinal cord). It is possible that voiding dysfunction after stress incontinence procedures is the result of partial denervation of the external sphincter or the urethra [91], and that these patients are ideal candidates for treatment with SNM $[1,92]$. Regarding previous back or SUI surgery, no clear statements can be made. In most studies, patients underwent back surgery for different indications. Also, in studies regarding prior SUI surgery, patients underwent different procedures which makes it difficult to compare all these results.

\section{Conclusion}

The results from the studies in this review are mixed and inconclusive because of the difference in patient population (gender, indication, and age), testing technique (type and duration), and primary outcome (test stimula- 
tion, long-term outcome, and AEs). Therefore, we could not make a general consensus on the possible factors leading to SNM success. Most studies were small and retrospective, and outcome measures differed between studies which limited the validity of the results. Furthermore, level of evidence of the included studies is low ( $3 b$ ), and prospective studies with larger sample sizes should further investigate factors that are associated with SNM outcome.

\section{Acknowledgement}

The authors would like to thank C. de Roest who contributed to the setup of the database.

\section{Statement of Ethics}

The research was conducted ethically in accordance with the World Medical Association Declaration of Helsinki. This systematic review was registered in PROSPERO under the number CRD42015016256.

\section{Conflict of Interest Statement}

The authors have no conflicts of interest to declare.

\section{Funding Sources}

There were no funding sources for this study.

\section{Author Contributions}

Ranjana Jairam and Jamie Drossaerts are first authors. Ranjana Jairam is the corresponding author. Ranjana Jairam and Jamie Drossaerts drafted this manuscript. Tom Marcelissen, Desiree Vrijens, Gommert van Koeveringe, and Phillip van Kerrebroeck revised it critically for important intellectual content and gave final approval of the version to be published. All of the authors read and approved the final version of this manuscript.

\section{References}

1 van Kerrebroeck PE, van Voskuilen AC, Heesakkers JP, Lycklama á Nijholt AA, Siegel S, Jonas $U$, et al. Results of sacral neuromodulation therapy for urinary voiding dysfunction: outcomes of a prospective, worldwide clinical study. J Urol. 2007;178(5):2029-34.

2 Siegel S, Noblett K, Mangel J, Bennett J, Griebling TL, Sutherland SE, et al. Five-year follow-up results of a prospective, multicenter study of patients with overactive bladder treated with sacral neuromodulation. J Urol. 2018;199(1):229-36.

3 Chartier-Kastler E, Le Normand L, Ruffion A, Dargent F, Braguet R, Saussine C, et al. Sacral neuromodulation with the InterStim System for Intractable Lower Urinary Tract Dysfunctions (SOUNDS): results of clinical effectiveness, quality of life, patient-reported outcomes and safety in a French multicenter observational study. Eur Urol Focus. 2020.

4 Koldewijn EL, Rosier PF, Meuleman EJ, Koster AM, Debruyne FM, van Kerrebroeck PE. Predictors of success with neuromodulation in lower urinary tract dysfunction: results of trial stimulation in 100 patients. $J$ Urol. 1994;152(6 Pt 1):2071-5.

5 Centre for Evidence-Based Medicine. Levels of evidence. University of Oxford: Medical Sciences Division; 2009.

6 Higgins JP. Cochrane Handbook for Systematic Reviews of Interventions. 2011.

7 Adelstein SA, Lee W, Gioia K, Moskowitz D, Stamnes K, Lucioni A, et al. Outcomes in a contemporary cohort undergoing sacral neuromodulation using optimized lead place- ment technique. Neurourol Urodyn. 2019; 38(6):1595-601.

8 Amundsen CL, Webster GD. Sacral neuromodulation in an older, urge-incontinent population. Am J Obstet Gynecol. 2002; 187(6):1462-5; discussion 1465.

9 Bertapelle P, Bodo G, Carone R. Detrusor acontractility in urinary retention: detrusor contractility test as exclusion criteria for sacral neurostimulation. J Urol. 2008;180(1): 215-6.

10 Cameron AP, Anger JT, Madison R, Saigal CS, Clemens JQ; Urologic diseases in America $P$. National trends in the usage and success of sacral nerve test stimulation. J Urol. 2011; 185(3):970-5.

11 Drossaerts J, Vrijens D, Leue C, Schilders I, Van Kerrebroeck P, van Koeveringe G. Screening for depression and anxiety in patients with storage or voiding dysfunction: a retrospective cohort study predicting outcome of sacral neuromodulation. Neurourol Urodyn. 2016;35(8):1011-6.

12 Jairam R, Drossaerts J, van Koeveringe G, van Kerrebroeck P. The impact of duration of complaints on successful outcome of sacral neuromodulation. Urol Int. 2017; 99(1):51-5.

13 Jairam R, Marcelissen T, van Koeveringe G, van Kerrebroeck P. Optimal lead positioning in sacral neuromodulation: which factors are related to treatment outcome? Neuromodulation. 2017;20(8):830-5.

14 Janknegt RA, Weil EH, Eerdmans PH. Improving neuromodulation technique for re- fractory voiding dysfunctions: two-stage implant. Urology. 1997;49(3):358-62.

15 Kessler TM, Madersbacher H, Kiss G. Prolonged sacral neuromodulation testing using permanent leads: a more reliable patient selection method? Eur Urol. 2005;47(5):660-5.

16 Saber-Khalaf M, Abtahi B, Gonzales G, Helal M, Elneil S. Sacral neuromodulation outcomes in male patients with chronic urinary retention. Neuromodulation. 2015;18(4): 329-34; discussion 334.

17 Bannowsky A, Wefer B, Braun PM, Jünemann KP. Urodynamic changes and response rates in patients treated with permanent electrodes compared to conventional wire electrodes in the peripheral nerve evaluation test. World J Urol. 2008;26(6):623-6.

18 Everaert K, Plancke H, Lefevere F, Oosterlinck W. The urodynamic evaluation of neuromodulation in patients with voiding dysfunction. Br J Urol. 1997;79(5):702-7.

19 Goh M, Diokno AC. Sacral neuromodulation for nonobstructive urinary retention: is success predictable? J Urol. 2007;178(1):197-9; discussion 199.

20 Killinger KA, Gupta P, Gilleran JP, Bartley J, Ehlert M, Boura JA, et al. The impact of baseline functional bladder capacity on shortterm neuromodulation outcomes. Urology. 2017;102:68-72.

21 Sherman ND, Jamison MG, Webster GD, Amundsen CL. Sacral neuromodulation for the treatment of refractory urinary urge incontinence after stress incontinence surgery. Am J Obstet Gynecol. 2005;193(6):2083-7. 
22 Amundsen CL, Romero AA, Jamison MG, Webster GD. Sacral neuromodulation for intractable urge incontinence: are there factors associated with cure? Urology. 2005;66(4): 746-50.

23 Anger JT, Cameron AP, Madison R, Saigal C, Clemens JQ; Urologic Diseases in America P. Predictors of implantable pulse generator placement after sacral neuromodulation: who does better? Neuromodulation. 2014;17(4): 381-4; discussion 384

24 Bross S, Braun PM, Weiss J, Martinez Portillo FJ, Knoll T, Seif C, et al. The role of the carbachol test and concomitant diseases in patients with nonobstructive urinary retention undergoing sacral neuromodulation. World J Urol. 2003;20(6):346-9.

25 Cohen BL, Tunuguntla HS, Gousse A. Predictors of success for first stage neuromodulation: motor versus sensory response. J Urol. 2006;175(6):2178-80; discussion 2180-1.

26 Leong RK, De Wachter SG, Nieman FH, de Bie RA, van Kerrebroeck PE. PNE versus 1st stage tined lead procedure: a direct comparison to select the most sensitive test method to identify patients suitable for sacral neuromodulation therapy. Neurourol Urodyn. 2011;30(7):1249-52.

27 Nguyen LN, Bartley J, Killinger KA, Gupta P, Lavin J, Khourdaji A, et al. Does sex matter? A matched pairs analysis of neuromodulation outcomes in women and men. Int Urol Nephrol. 2018;50(5):825-32.

28 Nobrega RP, Solomon E, Jenks J, Greenwell T, Ockrim J. Predicting a successful outcome in sacral neuromodulation testing: are urodynamic parameters prognostic? Neurourol Urodyn. 2018;37(3):1007-10.

29 Scheepens WA, de Bie RA, Weil EH, van Kerrebroeck PE. Unilateral versus bilateral sacral neuromodulation in patients with chronic voiding dysfunction. J Urol. 2002;168(5): 2046-50.

30 Scheepens WA, Jongen MM, Nieman FH, de Bie RA, Weil EH, van Kerrebroeck PE. Predictive factors for sacral neuromodulation in chronic lower urinary tract dysfunction. Urology. 2002;60(4):598-602.

31 South MM, Romero AA, Jamison MG, Webster GD, Amundsen CL. Detrusor overactivity does not predict outcome of sacral neuromodulation test stimulation. Int Urogynecol J Pelvic Floor Dysfunct. 2007;18(12):1395-8.

32 Weissbart SJ, Bhavsar R, Rao H, Wein AJ, Detre JA, Arya LA, et al. Specific changes in brain activity during urgency in women with overactive bladder after successful sacral neuromodulation: a fMRI Study. J Urol. 2018; 200(2):283-8.

33 Malaguti S, Spinelli M, Giardiello G, Lazzeri $M$, Van Den Hombergh U. Neurophysiological evidence may predict the outcome of sacral neuromodulation. J Urol. 2003;170(6 Pt 1):2323-6.

34 Borawski KM, Foster RT, Webster GD, Amundsen CL. Predicting implantation with a neuromodulator using two different test stimulation techniques: a prospective randomized study in urge incontinent women. Neurourol Urodyn. 2007;26(1): 14-8.

35 Gleason JL, Kenton K, Greer WJ, Ramm O, Szychowski JM, Wilson T, et al. Sacral neuromodulation effects on periurethral sensation and urethral sphincter activity. Neurourol Urodyn. 2013;32(5):476-9.

36 Groenendijk PM, Heesakkers JP, Lycklama A Nijeholt AA. Urethral instability and sacral nerve stimulation-a better parameter to predict efficacy? J Urol. 2007;178(2):568-72; discussion 572 .

37 Berthelot LP, Peyronnet B, Cornu JN, Aublé A, Brassart E, Bigot P, et al. Do failure of posterior tibial nerve stimulation precludes to use sacral neuromodulation in patient with overactive bladder? Int Neurourol J. 2019;23(4): 287-93.

38 Dobberfuhl AD, Mahal A, Dallas KB, Choi KM, Comiter CV, Elliott CS. Statewide success of staged sacral neuromodulation for the treatment of urinary complaints in California (2005-2011). Female Pelvic Med Reconstr Surg. 2020;26(7):437-42.

39 Gupta A, Kinman C, Hobson DTG, Meriwether KV, Gaskins JT, Uddin MN, et al. The impact of fluoroscopy during percutaneous nerve evaluation on subsequent implantation of a sacral neuromodulator among women with pelvic floor disorders: a randomized, noninferiority trial. Neuromodulation. 2020; 23(8):1164-71.

40 Drossaerts J, Rademakers K, van Koeveringe G, Van Kerrebroeck P. The value of urodynamic tools to guide patient selection in sacral neuromodulation. World J Urol. 2015;33(11): 1889-95.

41 Blandon RE, Gebhart JB, Lightner DJ, Klingele CJ. Re-operation rates after permanent sacral nerve stimulation for refractory voiding dysfunction in women. BJU Int. 2008; 101(9):1119-23.

42 Everaert K, De Ridder D, Baert L, Oosterlinck W, Wyndaele JJ. Patient satisfaction and complications following sacral nerve stimulation for urinary retention, urge incontinence and perineal pain: a multicenter evaluation. Int Urogynecol J Pelvic Floor Dysfunct. 2000; 11(4):231-5; discussion 236.

43 Greenberg DR, Syan R, Young-Lin N, Comiter CV, Enemchukwu E. Outcomes of sacral nerve stimulation for treatment of refractory overactive bladder among octogenarians. Neuromodulation. 2019;22(6):738-44.

44 Marcelissen T, Leong R, Serroyen J, van Kerrebroeck $\mathrm{P}$, de Wachter $\mathrm{S}$. Is the screening method of sacral neuromodulation a prognostic factor for long-term success? J Urol. 2011;185(2):583-7.

45 Marcelissen TA, Leong RK, Nieman FH, van Lankveld JJ, van Kerrebroeck PE, de Wachter SG. Psychological and psychiatric factors as predictors for success in sacral neuromodulation treatment. BJU Int. 2011;108(11):18348.
46 Arlen AM, Powell CR, Kreder KJ. Sacral neuromodulation for refractory urge incontinence is less effective following spinal surgery. ScientificWorldJournal. 2011;11:1426.

47 Bartley JM, Killinger KA, Boura JA, Gupta P, Gaines N, Gilleran JP, et al. The impact of prior back surgery on neuromodulation outcomes: a review of over 500 patients. Neurourol Urodyn. 2017;36(6):1535-42.

48 Bartley JM, Ramirez V, Killinger KA, Boura JA, Gupta P, Gaines N, et al. Outcomes of sacral neuromodulation in patients with prior surgical treatment of stress urinary incontinence and pelvic organ prolapse. Female Pelvic Med Reconstr Surg. 2017;23(1):8-12.

49 Faris AER, Gill BC, Pizarro-Berdichevsky J, Dielubanza E, Clifton MM, Okafor $\mathrm{H}$, et al. Impact of age and comorbidities on use of sacral neuromodulation. J Urol. 2017;198(1): 161-6.

50 Spinelli M, Weil E, Ostardo E, Del Popolo G Ruiz-Cerdá JL, Kiss G, et al. New tined lead electrode in sacral neuromodulation: experience from a multicentre European study. World J Urol. 2005;23(3):225-9.

51 Vaganee D, Kessler TM, Van de Borne S, De Win G, De Wachter S. Sacral neuromodulation using the standardized tined lead implantation technique with a curved vs a straight stylet: 2-year clinical outcomes and sensory responses to lead stimulation. BJU Int. 2019;123(5A):E7-13.

52 Yazdany T, Bhatia N, Nguyen J. Determining outcomes, adverse events, and predictors of success after sacral neuromodulation for lower urinary disorders in women. Int Urogynecol J. 2011;22(12):1549-54.

53 Kessler TM, Buchser E, Meyer S, Engeler DS, Al-Khodairy AW, Bersch U, et al. Sacral neuromodulation for refractory lower urinary tract dysfunction: results of a nationwide registry in Switzerland. Eur Urol. 2007;51(5): 1357-63.

54 Peters KM, Killinger KA, Boura JA. Is sensory testing during lead placement crucial for achieving positive outcomes after sacral neuromodulation? Neurourol Urodyn. 2011; 30(8):1489-92.

55 Peters KM, Killinger KA, Gilleran J, Boura JA. Does patient age impact outcomes of neuromodulation? Neurourol Urodyn. 2013;32(1): 30-6.

56 White WM, Mobley JD 3rd, Doggweiler R, Dobmeyer-Dittrich C, Klein FA. Sacral nerve stimulation for refractory overactive bladder in the elderly population. J Urol. 2009;182(4): 1449-52.

57 High RA, Winkelman W, Panza J, Sanderson DJ, Yuen H, Halder G, et al. Sacral neuromodulation for overactive bladder in women: do age and comorbidities make a difference? Int Urogynecol J. 2021;32(1):149-57.

58 Morgan TN, Pace N, Mohapatra A, Ren D, Kunkel G, Tennyson L, et al. Sacral neuromodulation: determining predictors of success. Urology. 2020. 
59 Schonburg S, Bukethal T, Fornara P. Does age alone negatively predict the outcome of sacral neuromodulation? A single-centre retrospective observational study. BMC Urol. 2020; 20(1):55.

60 De Ridder D, Ost D, Bruyninckx F. The presence of Fowler's syndrome predicts successful long-term outcome of sacral nerve stimulation in women with urinary retention. Eur Urol. 2007;51(1):229-33; discussion 233-4.

61 Gahzi AA, Banakhar MA, Elterman DS, Hassouna M. Radiographic position of the electrode as a predictor of the outcome of InterStim therapy. Int Neurourol J. 2017;21(4): 289-94.

62 Ismail S, Chartier-Kastler E, Perrouin-Verbe MA, Rose-Dite-Modestine J, Denys P, Phé V. Long-term functional outcomes of S3 sacral neuromodulation for the treatment of idiopathic overactive bladder. Neuromodulation. 2017;20(8):825-9.

63 Janknegt RA, Hassouna MM, Siegel SW, Schmidt RA, Gajewski JB, Rivas DA, et al. Long-term effectiveness of sacral nerve stimulation for refractory urge incontinence. Eur Urol. 2001;39(1):101-6.

64 White WM, Mobley JD 3rd, Doggweiler R, Dobmeyer-Dittrich C, Klein FA. Incidence and predictors of complications with sacral neuromodulation. Urology. 2009;73(4):7315.

65 Ghazwani YQ, Elkelini MS, Hassouna M. Association between stimulation parameters and loss of efficacy of selective sacral nerve root stimulation. Neuromodulation. 2011, 14(3):266-70.

66 Cameron AP, Anger JT, Madison R, Saigal CS, Clemens JQ; Urologic Diseases in America P. Battery explantation after sacral neuromodulation in the medicare population. Neurourol Urodyn. 2013;32(3):238-41.

67 Guralnick ML, Benouni S, O'Connor RC, Edmiston C. Characteristics of infections in patients undergoing staged implantation for sacral nerve stimulation. Urology. 2007;69(6): 1073-6.

68 Siddiqui NY, Amundsen CL, Corey EG, Wu JM. Lead migration after sacral neuromodulation: surgical revision in fascial versus tined anchoring systems. Int Urogynecol J. 2011; 22(4):419-23.

69 Weil EH, Ruiz-Cerdá JL, Eerdmans PH, Janknegt RA, Van Kerrebroeck PE. Clinical results of sacral neuromodulation for chronic voiding dysfunction using unilateral sacral foramen electrodes. World J Urol. 1998;16(5): $313-21$.
70 Groenendijk PM, Lycklama à Nyeholt AA, Heesakkers JP, van Kerrebroeck PE, Hassouna MM, Gajewski JB, et al. Urodynamic evaluation of sacral neuromodulation for urge urinary incontinence. BJU Int. 2008;101(3): 325-9.

71 Pizarro-Berdichevsky J, Gill BC, Clifton M, Okafor HT, Faris AE, Vasavada SP, et al. Motor response matters: optimizing lead placement improves sacral neuromodulation outcomes. J Urol. 2018;199(4):1032-6.

72 Kaaki B, Gupta D. Medium-term outcomes of sacral neuromodulation in patients with refractory overactive bladder: a retrospective single-institution study. PLoS One. 2020; 15(7): 0235961.

73 Noblett K, Berg KC, Kan F, Siegel S. Baseline symptom severity and therapeutic success in a large prospective trial of sacral neuromodulation therapy for overactive bladder patients. Neurourol Urodyn. 2018;37(5):1667-71.

74 Gamé X, Khan S, Panicker J, Hamid R, Elneil S, Fowler C. 2-stage sacral neuromodulation for treating chronic urinary retention in women: outcome and response prognostic factors. ICS Abstract. 2010.

75 Elneil SAB, Helal M, Khan S, Gonzales G. Two-stage sacral neuromodulation for chronic urinary retention in women: determination of prognostic factors that may affect outcome. ICS Abstract. 2014.

76 Powell CTE, Kreder K. Patient age predicts success in patients undergoing sacral neuromodulation for voiding dysfunction. Abstract ICS. 2009.

77 Ghazwani YEM, Hassouna M. Predictive factors for sacral neuromodulation outcome in non-obstructive urinary retention. ICS Abstract. 2010.

78 Scheepens WA, Van Koeveringe GA, De Bie RA, Weil EH, Van Kerrebroeck PE. Longterm efficacy and safety results of the twostage implantation technique in sacral neuromodulation. BJU Int. 2002;90(9):840-5.

79 Cerruto MA, Curti P, D’Elia C, Ostardo E, Pastorello M, Signorello D, et al. Role of symptoms duration as prognosticator for sacral neuromodulation in refractory overactive bladder. ICS Abstract. 2012.

80 Yoon H, Jun G. A short-term analysis of parameters affecting the outcome of sacral neuromodulation. ICS Abstract. 2014.

81 Blasco P, Moreno S, Almeida C, Rivera F, Lendínez G, Camacho E. Interstim therapy programming parameters. Do they have anything to do with positive tests? ICS Abstract. 2014.

82 Gousse A, Tunuguntla H. Can we predict IPG implant during first stage Interstim sacral tined-quadripolar neuromodulation? Should we value motor or sensory responses? ICS Abstract.
83 Rasmussen N, O'Connor RC, Szabo A, Eastwood D, Guralnick M. Sensory or motor responses: which are more important for predicting the success of sacral neuromodulation for the management of voiding dysfunction? ICS Abstract. 2011

84 Smits M, de Wachter S. Sacral neuromodulation therapy in patients with non obstructive urinary retention and history of bladder overdistension exceeding 1500cc. ICS Abstract. 2012.

85 Jacobs SA, Lane FL, Osann KE, Noblett KL. Randomized prospective crossover study of Interstim lead wire placement with curved versus straight stylet. Neurourol Urodyn. 2014;33(5):488-92

86 Coyne KS, Wein AJ, Tubaro A, Sexton CC, Thompson CL, Kopp ZS, et al. The burden of lower urinary tract symptoms: evaluating the effect of LUTS on health-related quality of life, anxiety and depression: EpiLUTS. BJU Int. 2009; 103(Suppl 3):4-11.

87 Quek KF. Factors affecting health-related quality of life among patients with lower urinary tract symptoms. Int J Urol. 2005;12(12): 1032-6.

88 Vrijens D, Drossaerts J, van Koeveringe G, Van Kerrebroeck P, van Os J, Leue C. Affective symptoms and the overactive bladder: a systematic review. J Psychosom Res. 2015; 78(2):95-108.

89 Dolat MT, Klausner AP. UROPSYCHIATRY: the relationship between overactive bladder and psychiatric disorders. Curr Bladder Dysfunct Rep. 2013;8(1):69-76.

90 Comiter CV, Mazar C, Phull H, Salkini M. Chronic sacral nerve stimulation prevents detrusor structural and functional changes associated with bladder outlet obstruction: a rat model. Neurourol Urodyn. 2010;29(5):7838.

91 Fowler CJ, Kirby RS, Harrison MJ. Decelerating burst and complex repetitive discharges in the striated muscle of the urethral sphincter, associated with urinary retention in women. J Neurol Neurosurg Psychiatry. 1985;48(10): 1004-9.

92 Kessler TM, Fowler CJ. Sacral neuromodulation for urinary retention. Nat Clin Pract Urol. 2008;5(12):657-66.

93 Scott A, Raybourne J, Rothschild J, Milam D, Dmochowski R, Reynolds W, et al. 10 year single institution experience with sacral neuromodulation. Abstract AUA. 2013. 